renew all its street lamps after a fixed number of hours of burning than to wait till each lamp burns out, and then send a man to replace it. For a number of years individual firms have here and there made use of statistical theory in laying out efficient research programmes to improve the quality of production or to establish sampling plans to reduce the cost of inspection. But it is only in the last few months that an attempt was made to organise concerted action, when the British Standards Institution appointed a small committee to investigate the problem from the point of view of standard. isation and specification. Direct contact between the industrialist and the statistician is of first importance. The former has not hitherto fully realised the potentiality of the statistical tool, while the latter has not understood the lines along which theory could be most helpfully developed.

\section{The Roman Wall in Scotland}

Aт the Friday evening discourse on December 16 at the Royal Institution, Sir George MacDonald discussed the Roman Wall in Scotland. So far as its chances of survival were concerned, the Wall was unfortunately situated. Stretching, as it did, from Forth to Clyde, it ran, for the most part, through arable land and also traversed what was destined to become a great industrial belt. Nevertheless its remains are still considerable. The date of its erection was about A.D. 142, soon after the accession of Antoninus Pius, and it is quite certain that it was abandoned before the end of the century. Soldiers say that, as a piece of military engineering, the line which it followed was admirable, much superior to that selected for the Wall of Hadrian. The barrier consisted of three main elements-a rampart, a ditch, and a military road-and there were nineteen supporting forts, planted at intervals which averaged two miles in length. Despite its excellent construction, the road has been destroyed almost everywhere. On the other hand, the ditch, which was usually about $40 \mathrm{ft}$. wide and 12-15 ft. deep, has left an enduring mark. Even where it has been entirely flled in, digging will always reveal its position. Within the last twenty years its course has been determined for practically the whole 37 miles of its length, and this will be noted on future issues of the Ordnance Survey maps. A group of seventeen inscriptions, unique in the Roman world, yields extremely interesting information as to the dis. tribution of the work among different bodies of legionaries. The purpose of the Wall is often misunderstood. What it contemplated was not a state of war, but a state of restless peace. Excavation has proved that the forts were twice evacuated and twice restored before the final abandonment, and has also brought us to some extent into personal touch with the men who maintained the pax Romana in North Britain in these troublous days. They were not Romans, in the strict sense of the term, but a motley crew, levied chiefly in Gaul and the Low Countries, having Latin as a common language and welded into a unity by iron discipline.

\section{A New Academy of Sciences in Western China}

Three years ago there was organised in the Little Gorges near Chungking of Szechuan province an Academy of Sciences of Western China. This institute is supported primarily by private contributions. It has now an annual budget of 40,000 Mexican dollars. Research and survey work along the lines of geology and biology will be pursued in the Academy. At present, with the help of Dr. H. H. Hu, director of the Fan Memorial Institute of Biology at Peiping, a herbarium and a botanical garden have been established by the Academy, with the view of exploring botanically all parts of that vast province and eastern Tibet, and collecting seeds, cuttings, and bulbs, etc., for planting in the botanical garden. It is intended shortly to establish a nursery where seeds and bulbs will be provided for sale or exchange. For example, the collector was instructed to collect seeds of Rehderodendron, a new genus of three species of ornamental trees of Styracaceæ, recently described by Dr. Hu. Seeds of other interesting and ornamental plants will also be collected. The Armold Arboretum of Harvard University will be the first botanical institute in the United States of America to share a part of this collection. This year two parties have been sent out by that institute to collect herbarium specimens and seeds, one to eastern, another to southwestern Szechuan. The latter is exploring the bordering districts along the Szechuan-Yunnan-Tibet borderland. In the winter the collector will bring herbarium specimens and seeds to the Fan Institute for study and identification, as that institute has a large herbarium and a large botanical library, and furthermore a unique collection of some 17,000 photographs of the type-specimens of Chinese and other Asiatic countries taken in various European herbaria.

\section{"Terrestrial Magnetism and Atmospheric Electricity"}

The September issue of Terrestrial Magnetism and Atmospheric Electricity forms a memorial number in honour of the late Dr. Louis A. Bauer, who founded the journal in 1896 and edited it almost until his death early this year. It contains two admirable portraits of Dr. Bauer. The number is of unusual length, containing 220 pages, and (besides subsidiary matter) thirty-seven articles by authorities on terrestrial magnetism and electricity from all over the world. Some of these are of unusual interest, and among them may be mentioned those of Adolph Schmidt, J. Bartels, and L. Vegard. Sohmidt deals with the secular magnetic variation, and shows that many of its larger features can be explained in a simple way as due to the rotation of a component of magnetic polarity, about an axis through the points where the Greenwich meridian crosses the equator, so that the poles of this component move in the meridians of longitude $90^{\circ}$ and $270^{\circ}$, the complete rotation taking about 480 years. This simple conception explains the main features of the secular variation but does not agree so well with the longcontinued decline of the earth's magnetic moment during several decades past. The article by Bartels 